\title{
Viability of carbon offset-generating afforestation projects in boreal Ontario
}

\author{
by Jeffrey Biggs ${ }^{1}$ and Susanna Laaksonen-Craig ${ }^{2}$
}

\begin{abstract}
Carbon offsets generated under the Kyoto Protocol (KP) should be included in the management options considered by resource managers. This paper investigates investments in afforestation for the generation of KP-compliant carbon offsets in the Timmins Management Unit, concentrating on the availability of quality carbon budget models, domestic carbon market concerns and the presence of an enabling environment. A modelling exercise is undertaken using GORCAMWC1, with ownership, leading species, investment horizon, site productivity and carbon price as variables. Under current institutional frameworks, afforestation projects with the purpose of generating carbon offsets in the TMU are not viable investments for the first commitment period, though such projects will be profitable under certain conditions if constraints are removed and investment is long term.
\end{abstract}

Key words: afforestation, Kyoto Protocol, boreal Ontario, carbon sequestration

\begin{abstract}
RÉSUMÉ
Les retraits de carbone générés sous le Protocole de Kyoto (PK) devraient être inclus parmi les options d'aménagement envisages par les gestionnaires des ressources. Cet article étudie les investissements en reboisement dans le but de produire des retraits de carbone conforme au PK dans l'unité d'aménagement de Timmins en s'attardant principalement sur la disponibilité de modèles valables de comptabilisation du carbone, les questions du marché domestique du carbone et la présence d'un environnement favorable. Un exercice de modélisation est effectué au moyen du GORCAM-WC1, la tenure, les principales espèces, la durée de l'investissement, la productivité de la station et la valeur du carbone étant les variables. En fonction des cadres de référence institutionnels actuels, les projets de reboisement visant le retrait de carbone dans la région de Timmins ne constituent pas un investissement viable au cours de la première période d'engagement, mais de tels projets seront profitables sous certaines conditions si des contraintes sont retirées et que l'investissement se fasse à long terme.
\end{abstract}

Mots clés : reboisement, Protocole de Kyoto, Nord de l’Ontario, séquestration du carbone

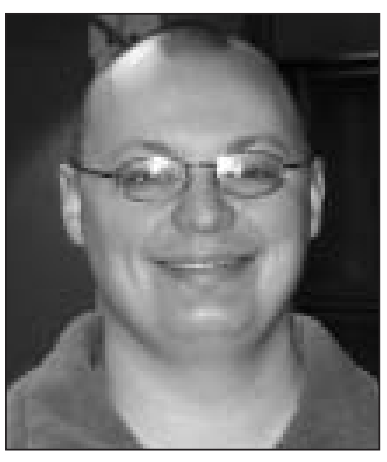

Jeffrey Biggs

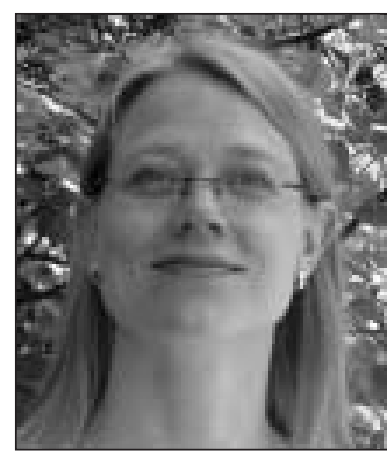

Susanna Laaksonen-Craig

\section{Introduction}

The Kyoto Protocol (KP) arose out of the recognition by the United Nations Framework Convention on Climate Change (UNFCCC) that traditional legislative means of protecting environmental services are inadequate, and it was hoped that the KP would provide enforceable goals for reducing the

atmospheric concentration of greenhouse gases (GHGs). Countries with GHG abatement targets for the first commitment period (CP1: 2008-2012) have several options to meet their objectives: increased energy efficiency, conversion to renewable energy forms, forestry, agriculture and afforestation, and can do so using fiscal incentives, taxes and caps on GHG-producing industries.

In order to harmonize marginal abatement costs spatially, and thereby minimize total cost, mechanisms are being created to produce tradable carbon offsets that represent sequestered $\mathrm{CO}_{2}$. These offsets allow sequestration and emission abatement to occur in regions where it is most cost-effective, and also provide a financial incentive for landowners and resource managers to promote carbon sequestration as an economically viable activity (Bahn et al. 2001).

The forestry-related options to generate offsets are afforestation (Article 3.3) and forest management (Article 3.4). Despite a difference in definition ${ }^{3}$, both reforestation and afforestation are governed by the same rules for offset production, and are hereafter referred to as "afforestation" to distinguish them from planting as a silvicultural treatment

\footnotetext{
${ }^{1}$ Ph.D. Student, University of Toronto, Faculty of Forestry. Email jeffrey.biggs@utoronto.ca

${ }^{2}$ Assistant Professor, University of Toronto, Faculty of Forestry, 33 Willcocks St., Toronto, Ontario M5S 3B3. E-mail: susanna.laaksonen. craig@utoronto.ca

${ }^{3}$ Under the KP, reforestation is the act of establishing tree cover on land that has been historically forested, but not since 1990, while afforestation occurs when the same activities establish forests on land that has been without trees for significantly longer.
} 
after harvest, commonly referred to in the forest industry as reforestation. There is no cap on the amount of domestic afforestation that Canada can apply towards its KP commitment, unlike forest management.

Carbon sinks have the potential to play a significant role in meeting KP targets. The federal government of Canada committed to decrease national emissions to $6 \%$ below 1990 levels by the end of $\mathrm{CP} 1$, representing $~ 572 \mathrm{Mt}-\mathrm{CO}_{2}$-eq (Gunter et al. 1998). Various actors have claimed that its large land base and developed forest industry means that Canada can not only meet significant amounts of its KP commitments through afforestation, but that it will be a seller on the international offset market (Bernoux et al. 2002). The Canadian federal government has recognized this potential (Forest Sector Table 1999, Van Kooten et al. 1999). ${ }^{4}$ Though several papers have discussed national and provincial opportunities for such activity (e.g. Cherry 2001, McKenney et al. 2004) none have examined the requirements necessary for the generation of KP-compliant carbon offsets through afforestation for individual management units, outlining the specific steps necessary for an individual forest manager. This paper fills that gap, examining the unique characteristics of the Timmins Management Unit (TMU) in Northeastern Ontario and identifying the circumstances within which an investment in afforestation for carbon offset production would be reasonable, the profit that such a project could expect and the amount of carbon that would likely be sequestered. The paper is organized as follows. First, the practical requirements for the generation of carbon offsets through afforestation are discussed, with particular emphasis on modelling tools, markets and the institutional environment. Second, the unique characteristics of the TMU are considered and modelling assumptions are presented. Finally, scenarios are developed and executed, and the results are discussed.

\section{Requirements for Offset-generating Afforestation Projects}

A resource manager considering investing in afforestation for the generation of KP-compliant carbon offsets will base the decision on the presence, form and quality of three things: 1 . credible monitoring and modelling tools, 2 . the nature of the domestic carbon market, and 3. an enabling environment. Credible monitoring is necessary in order to quantify the number of carbon offsets generated by a project, whereas the domestic carbon market controls the value of those offsets and the rules under which they are exchanged. An enabling environment affects the confidence of a project manager that the return on an investment can be estimated in advance. Without these elements a manager does not have the information necessary to assess the viability of an afforestation investment. This section examines these elements with specific reference to the TMU.

\section{Credible models}

Models that estimate the change in carbon sinks over time rather than actually monitoring them are necessary because current technology does not allow for accurate landscape measurement of carbon flux at practical timescales.

${ }^{4}$ It has yet to say exactly how much. Figures range from $15 \%$ to 40\% (Cherry 2001, Griss 2002).
Development and improvement of such models would alleviate the problems associated with monitoring ecosystem carbon for KP compliance. For a carbon budget model (CBM) to be compliant with both the KP and the best available carbon science, it should be able to predict carbon flux for at least 11 ecological carbon pools (ArborVitae 1999). In addition, the CBM must be spatially explicit to the stand level, transparent with verifiable algorithms, adaptable to changing definitions and procedures, cost and time efficient, and able to interpret the past and project the future (Kurz 1999). Perhaps most importantly, CBMs must be available and easy to use so that a manager can predict the effects of proposed management on carbon balances accurately and with a minor investment in resources.

A number of CBMs approach these requirements, though none meet them exactly. GORCAM is available, easy to execute and has been used to predict management unit scale carbon budgets in Canada. It models nine of the required sinks, but lumps three soil sinks into a single value making it compliant to the minimum KP standard if not reflecting the most up-to-date science (Bird 2003). It uses the ChapmanRichards formula to convert merchantable volume to biomass, but the user supplies expansion factors, growth curves and average yearly temperature. ${ }^{5}$ This requires a not insignificant amount of work by the user. Furthermore, existing management plans in electronic format (e.g., Woodstock) cannot be input directly into the model, requiring a duplication of data input effort. Given the likelihood of high international scrutiny for projects claiming removal units, it is uncertain that GORCAM and similar models will meet global standards.

The weaknesses of GORCAM and other CBMs have been recognized for several years, and as a result the Canadian Forestry Service (CFS) has been developing a new version of its CBM (the CBM-CFS3). It will not only include all 11 ecological sinks, but provides Kyoto-specific outputs, includes growth curves and biomass expansions for all tree species found in Canada for all climatic zones and site classes and allows users to import management plans from both the Strategic Forest Management Model and Woodstock. Furthermore, it has been developed by a team that participates in the development of KP reporting requirements and is responsible for developing compliant Canadian systems. As a result, it requires significantly less time to produce results than other models and the results are likely to have more credibility.

\section{Domestic carbon market}

Much like the carbon budget models, the domestic carbon market is under development, and has yet to be brought online. From a more theoretical standpoint, Sandor et al. (2002) argue that a carbon credit market already exists, for there is a demand for capital to address a specific objective and some norms for trade and participation have been developed. However, the exact form of the market mechanisms have yet to be determined, though a significant effort internationally is currently underway involving the creation of pilot markets. Pilot markets allow assumptions to be tested, verification

${ }^{5}$ Interested readers may refer to Schlamadinger and Marland (1996) for a thorough examination of GORCAM and its equations. 
strategies to be honed, participation to be gauged and mechanisms to be evaluated before final markets are in place, which is critical given the sums of money likely to be invested (Bernard and Vielle 2003).

Analysis of pilot market mechanisms, especially the European Trading Scheme (ETS), the UK Climate Change Levy (CCL) and the Chicago Climate Exchange (CCX) reveal the likely shape of the market (Christiansen and Wettestad 2003 and Varma 2003). The extremely successful US Clean Air Act Amendment to restrict emissions of $\mathrm{SO}_{\mathrm{x}}$ has also been widely used as a template and will continue to be influential (Bonnie et al. 2002). That is, domestic markets will have mandatory participation of all major emitters with sectoral caps and trade. In initial stages, emission permits will be grandfathered on the basis of historical emissions, though auction-based allocation is more economically efficient. Perhaps most importantly, these new markets will not be based solely on government environmental policy, but will be worked out in dialog with a variety of public, private and transnational partners. As a result of these characteristics, demand for domestic carbon offsets is virtually guaranteed and the Canadian government will likely encourage new projects rather than simply endorsing old ones (Bernoux et al. 2002, White and Kurz 2003). However, despite recent efforts to define systems such as the Large Final Emitters Group and the Climate Fund of the federal government, there is currently no functioning domestic market in Canada (Canada 2005). Since the exact characteristics of this market are unknown, benefits are not guaranteed and uncertainty is high.

From a cost perspective, trees have been tended and planted in Northeastern Ontario for a significant length of time, and therefore, the costs of afforestation in the TMU are well understood. When site preparation, seedling purchase, planting and tending costs are included, DeMarsh (1999) identified an average cost around $\$ 1500 / \mathrm{ha},{ }^{6}$ in accordance with similar values provided by van Kooten et al. (1999) and Griss (2002). However, since carbon offsets have never been traded before, the benefits accruing to sellers are much less certain. Significant debate has occurred in economic literature as to the price of credits, but modelling and initial sales create a likely international price range from 2 to $7.5 \$ / \mathrm{t}-\mathrm{CO}_{2}$-eq (Sager 2003, Lecocq and Capoor 2005).

\section{Enabling environment}

An enabling environment consists of the physical and institutional structures that facilitate projects generating KP-compliant carbon offsets through afforestation. They include extension work by various levels of government, afforestation expertise, willingness among resource managers and a suitable land base for afforestation activities. Although the government of Canada was a major proponent of securing recognition from the international community that the benefits of carbon sinks should be included in the KP, it has taken little action to date to promote them domestically (Griss 2002). At least part of this delay can be attributed to conflict with provincial governments who see environmental considerations and resource management as a uniquely provincial concern. Furthermore, the government of Ontario has made afforestation of both private and public lands difficult

\footnotetext{
${ }^{6}$ All monetary figures in this paper are reported in Canadian dollars.
}

through the cancellation of provincially operated afforestation related programs $s^{7}$, though it did introduce the Managed Forest Tax Incentive Program (MFTIP) (Williams and Griss 1999, Cherry 2001). This effort has been hindered by municipal governments, however, which have refused to direct municipal tax assessors to reassess privately held land under MFTIP guidelines, resulting in tax burdens for those wishing to convert their land to forest (Miller and Balsillie 2003). When these institutional problems are combined with uncertainty relating to the carbon market, they make it difficult to pursue afforestation for the generation of KP-compliant carbon offsets in management units such as Timmins, leading some researchers to conclude that afforestation under the KP may be very small (Duinker et al. 1999).

In general, polls conducted throughout Ontario in 2000-2001 indicate that landowners are willing to participate in afforestation programs, with interest increasing as the size of the area owned decreases (Cherry 2001). The characteristics of such a program are important, with partnerships between landowners, government agencies and forest companies and significant subsidies (90\% of costs) required for program success (DeMarsh 1999). Under this sort of arrangement, where a government subsidy pays $90 \%$ of costs, one would assume that revenues from carbon sequestration would also accrue to the government, but if profitability was well understood and established beforehand, it is likely that managers would be less adamant about subsidies. If the effectiveness of MFTIP could be increased or further tax incentives given, willingness among managers would likely increase further (Griss 2002).

\section{Offset Generation in the TMU Timmins Management Unit}

The $\mathrm{TMU}^{8}$ consists of 200000 ha of land in Northeastern Ontario and borders the Iroquois Falls Forest Management Unit. The forestry activities on each are managed by AbitibiConsolidated. The forests are dominated by black spruce on moist lowland sites, jack pine on uplands, and trembling aspen on dry sites. Though most of the TMU is forested, significant areas of muskeg, cities (Timmins) and treeless fields also exist.

The area of suitable land for afforestation in the TMU is actually quite small if land currently under agricultural management is excluded. In this study agricultural land is excluded because the managers of agricultural land in Ontario are willing to consider afforestation only if it is accompanied by significant government subsidies (DeMarsh 1999, van Kooten et al. 1999). As this paper concentrates on the decision-making process of an individual project manager without government intervention, lands that would require a subsidy for afforestation are not considered in the analysis.

Areas in the TMU suitable for afforestation under these criteria were determined from ArcView 3.2-based land use files as provided by Abitibi Consolidated and the Lake Abitibi

\footnotetext{
${ }^{7}$ In late 2004 the Ontario government announced a small pilot afforestation program called Forests 2020 to be administered by Trees Ontario. Planting under this program commenced in mid2005.

${ }^{8}$ Note that in 2003 the TMU was amalgamated with the Timmins Forest and Driftwood Forest into the Nighthawk Forest, under which title it is currently being managed.
} 
Model Forest. Those that fell under the categories of "meadows" or "brush and alder" were considered suitable and were distinguished according to ownership class. There are 40 ha of privately owned suitable land, and 4000 ha of publicly owned suitable land. ${ }^{9}$

The prevailing climate regime has a significant effect on ecosystem productivity and carbon sequestration and typically the complex relationships between ecosystem and climate are simplified to one or two parameters. In this paper, average annual temperature as recorded at Cochrane, Ontario, by Environment Canada for the last 30 years was used.

Climate change has been predicted to increase drought stress, wildfire intensity and wildfire duration in Ontario's boreal forest (Stocks et al. 1998). It is difficult to predict the response of ecosystem productivity to these changes, however, with various researchers forecasting either increased sequestration or increased emissions depending on which soil processes they think are most significant. Due to the uncertainty, the best response is to select species for planting that are less susceptible to the likely future conditions of drought stress and increased fire activity. As a result of biodiversity and invasive species concerns, only native species are acceptable (Stiers and Siebert 2002). ${ }^{10}$ The most likely native species available for afforestation in northern Ontario, as identified by Cherry (2001), were therefore considered.

White and red pine show promise in boreal regions, with high productivity at young ages, but some research has shown that their impact on soil organic carbon is less desirable than other species (Vesterdal et al. 2002). Black and white spruce have the highest productivity of species found in the TMU, especially considering their high litterfall mass and relatively rapid growth, but are susceptible to the dry conditions potentially faced in the TMU under climate change (Chen et al. 2002). Jack pine and trembling aspen are the best suited for afforestation in the TMU given the conditions likely to be created by climate change since they both grow well under dry conditions and can have high short-term sequestration. A mix of $50 \%$ jack pine and $50 \%$ trembling aspen were therefore chosen for afforestation in these modelling scenarios, which is in line with the recommendations of Duinker (1999) and Cherry (2001). There is no difficulty in getting these species from local seed zones (Cherry 2001).

Though under the KP aboveground tree biomass is considered to be $100 \%$ emitted to the atmosphere upon harvesting, harvest does not necessarily result in a net emission when the entire landscape and belowground carbon sinks are considered. It is therefore possible to balance the economic returns from harvest against those of carbon sequestration to maximize revenue generation, and to use carbon models to contribute to the determination of optimal rotation ages and silvicultural treatments (Peng et al. 2002). The long-term effects can also be identified, for though many carbon pools recover quickly from disturbance, some are sources not only for the year they occur, but for years to come (Chen et al.

\footnotetext{
${ }^{9}$ Private land was excluded from the modelling exercise because of its low area relative to public land.

${ }^{10}$ Though the afforestation of hybrid poplar has become popular because of its quick growth, it requires careful tending, moist conditions, is prone to insect outbreak and disease, and has not responded well in experimental plantings in Northern Ontario (Samson et al. 1999, Cherry 2001, Perry et al. 2001).
}

2002). Despite the obvious value of studying the effect of disturbance on carbon stocks, however, these scenarios do not include it. The purpose of this exercise is to determine whether afforestation for the generation of carbon credits in and of itself is a reasonable investment in the TMU. We do not examine all the potential revenue streams that could accrue to such a project. It should nonetheless be remembered that there are other benefits to afforestation projects than simply KP-compliant offsets.

Soil characteristics are critical for landscape-scale carbon modelling because globally soils contain approximately three times as much carbon as terrestrial vegetation and have the longest residence time of terrestrial pools, especially in boreal forests (Bhatti et al. 2002). In particular, the history of the area to be afforested is important, because soil respiration and decay will continue decades after aboveground biomass has been removed, and will have important effects on the timing and value of the steady-state soil carbon after an area has been afforested (Bashkin and Binkley 1998). The amount of soil carbon lost when forest is converted to agriculture is between $20 \%$ and $40 \%$, regardless of initial carbon content or soil texture, with the vast majority lost within the first 20 years (West and Post 2002). In this study, since the only fields under consideration have been cleared for over 25 years and are not currently managed for agriculture, the main effects of deforestation have already occurred, so a current soil carbon value is sufficient.

Another soil value important to this study is productivity, including available soil nutrients, relief, some climatic factors and drainage, all of which are summarized by site class (Marland and Schlamadinger 1997). Based on the recommendation of Duinker (1999), a high site class value for these lands was assumed (Site Class 1, SC1), but a lower class was also modeled for comparison (Site Class 2, SC2). Duinker (1999) recommends a high site class because forests cleared for agriculture or pasture typically represent the most productive lands in an area. Drainage is therefore assumed not to be a constraint, since lands where drainage is a serious problem would be classified as "muskeg" and therefore not considered. Furthermore, yearly totals are considered rather than continuous tracking of carbon levels, because there are important seasonal differences between whether a landscape is a site or sink.

Regardless of soil characteristics and without minimizing their importance on carbon stocks over the landscape, it is important to remember that soil pools are stable over the long term, and increase slowly even when biomass increases quickly (Seely et al. 2002). Studies indicate that in scenarios like those being analyzed here, soil carbon will increase significantly (mainly from inputs of forest litter) but only 100 to 200 years after afforestation (Vesterdal et al. 2002). As a result, the contribution of soil is not likely to be significant in the TMU over the short and medium term.

\section{Modelling tools and scenarios}

GORCAM-WC1 is used in this study; it is an Excel-based, stand-level version of GORCAM supplied by Woodrising Consulting Incorporated of Belfountain Ontario. Merchantable volume growth curves were those of Plonski (1974), taken with biomass expansion factors from Alemdag $(1983,1984)$ and Krcmar et al. (2001) based on the method- 
Table 1. Modelling scenarios

\begin{tabular}{lllllllll}
\hline Variable & S1 & S2 & S3 & S4 & S5 & S6 & S7 & S8 \\
\hline Area (ha) & 4000 & 4000 & 4000 & 4000 & 4000 & 4000 & 4000 & 4000 \\
Productivity & SC1 & SC1 & SC1 & SC1 & SC2 & SC2 & SC2 & SC2 \\
Project Length & $2006-$ & $2006-$ & $2006-$ & $2006-$ & $2006-$ & $2006-$ & $2006-$ & $2006-$ \\
& 2014 & 2014 & 2056 & 2056 & 2014 & 2014 & 2056 \\
Costs (\$/ha) & 1500 & 1500 & 1500 & 1500 & 1500 & 1500 & 1500 & 1500 \\
Price $(\$ /$ t-CO - -eq) & 2 & 7.5 & 2 & 7.5 & 2 & 7.5 & 2 & 7.5 \\
\hline
\end{tabular}

ology of Bird (2003). Though the weaknesses of GORCAM described previously are significant, it has been used in these types of applications before and is representative of the best tools currently available.

In the modelling exercise it is assumed that afforestation in the TMU is immediate (beginning in 2006) on 100\% of the available landbase emulating the decision of an individual manager of a tract of land rather than a provincial program. The areas considered have not been actively managed for over 20 years and support little aboveground biomass with negligible potential for sequestration in the absence of the project. This allows the establishment of a steady-state baseline and removes the necessity of subtracting establishment emissions and forgone sequestration from final production. The effect of the project is considered over both a short-term (eightyear) and long-term 50-year (2006-2056) project timeline. Table 1 summarizes the characteristics of the modelling scenarios. The entire area is publicly owned, and planted stock is a 50/50 mix of jack pine and trembling aspen. The species mix remains constant across all scenarios.

In these scenarios, the only costs considered are the costs of afforestation itself. Though some researchers have noted that opportunity and transaction costs must be considered, and that they are extremely problematic, these were not included in this analysis (van Kooten et al. 1999). Opportunity cost is not significant in this case because the lands under consideration have not been under active management for some time. Therefore, there are no alternative uses in competition with afforestation whose potential revenue could be called an opportunity cost. ${ }^{11}$ It could be argued that a new project with no opportunity costs could not possibly be executed on a high site class site - as a profitable activity would surely already be in place. This is only a problem if standard rationality assumptions fully reflect reality — which they do not. Many managers have opportunities for profit that they do not pursue simply because they are engaged in other activities or the possibility had not occurred to them. Not only does the KP provide a financial incentive to execute a project, it also provides the impetus to overcome institutional inertia and act on viable projects yet to be realized. Transaction cost has not been considered because little is known about the nature of these costs in a KP-compliant project, though studies suggest that they could be low relative to expected returns (Sager 2003, Marbek Resource

\footnotetext{
${ }^{11}$ If a provincial afforestation program were being designed, however, opportunity costs would likely be the single most important factor influencing the participation of resource managers (DeMarsh 1999).
}

Consultants 2004). If it is determined by future research that they are important, they could easily be incorporated into similar modelling exercises.

\section{Modelling Results}

The results of the modelling scenarios are shown in Table 2 and Fig. 1. The results clearly indicate that the higher the productivity of the site, the more carbon is sequestered. A comparison of scenarios S4 and S8 that differ only in productivity implies that the difference between SC1 and SC2 is approximately $50 \%$ of the value of the latter. A similar significant impact was found by Duinker (1999).

One of the most significant impacts on sequestration is the timescale of the project. Table 2 clearly shows the impact time has on carbon accumulation. A 10-fold increase in project length results in over a 100-fold increase in carbon sequestered in some cases. Fig. 1 also demonstrates this effect clearly. Since the accumulation of aboveground biomass is the major driver of increases in ecosystem carbon in the first century of an afforestation project, it is clear from these results that the slow growth of native trees in the TMU means that afforestation projects will not generate carbon benefits in CP1.

The results indicate that ecosystem carbon accumulates faster in both trembling aspen and jack pine plantations at SC1 than SC2, which is not surprising. What is more interesting is that in the long term, SC2 trembling aspen sites accumulate more carbon than SC1 jack pine, indicating that, regardless of project length and site class, from a purely carbon-oriented perspective, managers should consider trembling aspen superior to jack pine. Given Duinker's (1999) recommendation to assume a high site class, and Betts' (2000) observation that plantations generally have higher sequestration potential than natural forests at mid to high latitudes,

Table 2. Results of the modelling exercise

\begin{tabular}{lrr}
\hline Scenario & Carbon Sequestered (tonnes) & Profit/Loss $(\$)$ \\
\hline S1 & 4030 & -5970000 \\
S2 & 4030 & -5880000 \\
S3 & 606000 & -1150000 \\
S4 & 606000 & 12200000 \\
S5 & 1310 & -5990000 \\
S6 & 1310 & -5960000 \\
S7 & 474000 & -2210000 \\
S8 & 474000 & 8230000 \\
\hline
\end{tabular}

${ }^{\text {a }}$ Conversion from mass of carbon to mass of $\mathrm{CO}_{2}$ uses the conversion factor 3.67 $\mathrm{t}-\mathrm{CO}_{2}: 1 \mathrm{t}-\mathrm{C}$. 


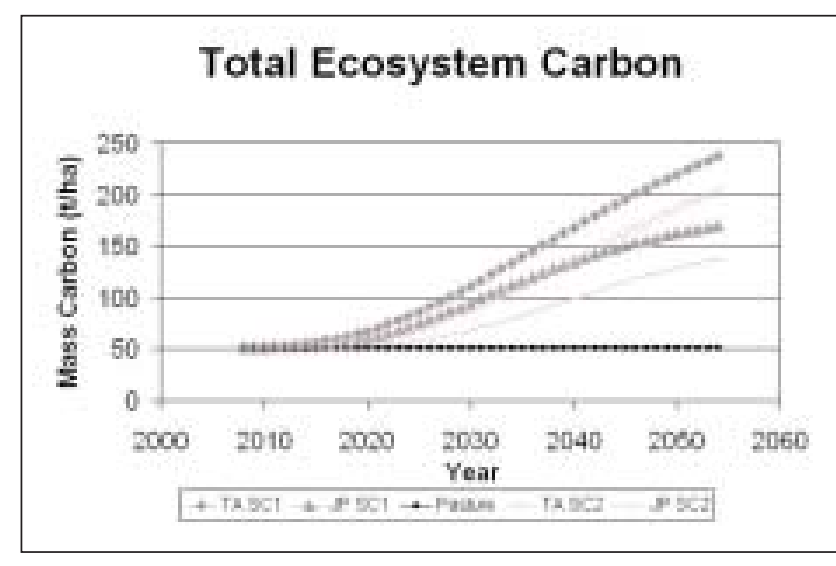

Fig. 1. Total ecosystem carbon under various site classes.

assuming high productivity seems reasonable. However, managers should carefully consider whether this assumption is warranted in their particular case, given the effect poor site class could have on their project. Fig. 1 demonstrates that site class assumptions are not the primary determinant of profitability, which is clearly the duration of the project.

Examining the role of offset price in the exercise reveals several important aspects of TMU afforestation projects. First, for all scenarios describing short term projects, that is S1, S2, S5 and S6, both the highest and lowest likely price yield money losing projects. In fact, the break even offset price is 1 $150 \$ / \mathrm{t}-\mathrm{CO}_{2}$-eq, a ludicrously high price that could not possibly be reached even though prices are expected to rise in future commitment periods (Griss 2002). Clearly, price is insignificant for short-term projects and no afforestationbased offset-generating project in the TMU will yield a profit in CP1. Second, the long-term price is very important, as indicated by the difference between S3 and S4 or S7 and S8. Depending on the price in future CPs, afforestation projects in the TMU could be quite profitable. In the SC1 scenarios, the break-even price for long-term investment is only 2.50 $\$ / \mathrm{t}-\mathrm{CO}_{2}$-eq and for SC2 only $3.20 \$ / \mathrm{t}-\mathrm{CO}_{2}$-eq, both very close to the minimum expected price. Therefore, though in the short term price is insignificant, in the long term it is a critical control on project viability.

An important assumption that has a significant impact on the results is the timing of benefits. Afforestation costs are assumed to occur up-front, in the first year of activities, which is reasonable. However, revenues are also assumed to occur in the first year of the project, which does not reflect reality. Under the KP, offsets generated from sequestration cannot be banked between CPs (Schulze et al. 2002). Therefore, only offsets already generated can be sold on the market. While this may leave room for a project manager signing a long-term contract with a buyer to supply them with a certain number of offsets over the next 50 years, it will certainly limit the buyer's use of those offsets to those already extant, which may make them unwilling to purchase credits up-front. If the present value of offsets at a 5\% interest rate sold in future CPs is considered ${ }^{12}$, S3 would lose $\$ 4.9$ million rather than $\$ 1.2$ million and S4 would lose \$2.0 million rather than make $\$ 12.2$ million. The break even price becomes $\$ 11.30 / \mathrm{t}-\mathrm{CO}_{2}$-eq.

${ }^{12}$ Assuming nine five-year CPs starting in 2008 and ending in 2052.
It should be noted that though this price is higher than the maximum price considered likely for $\mathrm{CP} 1$, it is projected that in future CPs offset price will rise to at least this much (Williams and Griss 1999). ${ }^{13}$ Therefore, prices will have to rise considerably higher than those predicted for CP1 if managers in the TMU are to be willing to invest in afforestation for carbon offset-generating projects.

\section{Conclusions}

The unique results of this analysis demonstrate that under quite reasonable conditions, that is a high price in future CPs and a few thousand hectares of unused land of high site class afforested using native species, afforestation projects are viable investments in the Timmins Management Unit even when the only revenue generated is from carbon offset sales. These results can be expected to hold in similar circumstances in much of boreal Canada. However, since it takes such a long time in these areas to accumulate significant amounts of carbon, activity should commence immediately for afforestation projects to return a profit in the near future.

The overriding theme through this analysis has been uncertainty. Current carbon models may be adequate for KP modelling and better models should be coming soon. The nature of the market can be approximated, and the future value of offsets produced can be predicted to a certain extent. That is, the future for such projects may be bright, or it may not. The major cause of this uncertainty is weakness in the enabling environment and a lack of clarity on the nature of the market. Until the market has been well defined and programs have been instituted at all institutional levels to promote afforestation, this analysis demonstrates that resource managers in the TMU, and potentially elsewhere in Canada, will have no incentive to participate in offset-generating afforestation projects not only during CP1, but for future CPs as well. This is not surprising considering the low growth rates found throughout much of Canada, and is in line with previous results.

\section{Acknowledgements}

Valuable comments from G.C. van Kooten, John Caspersen and two anonymous reviewers, and funding from the University of Toronto, Faculty of Forestry and from the SSHRC/ BIOCAP project "The economics of terrestrial carbon sinks: land use, land-use change and forestry" are gratefully acknowledged.

\section{References}

Alemdag, J. 1983. Mass equation and merchantability factors for Ontario softwoods. Petawawa National Forestry Institute, Chalk River, ON. Information Report. PI-X-23.

Alemdag, J. 1984. Total tree and merchantable stem biomass equations for Ontario hardwoods. Petawawa National Forestry Institute, Chalk River, ON. Information Report. PI-X-46.

\footnotetext{
${ }^{13}$ Though the costs/benefits of the project are discounted, the volume of carbon sequestered is not. The purpose of discounting is to indicate time preference for the commodity involved, which is obvious in the case of money but less so for carbon. There is no clear social preference for carbon sequestered today over that sequestered 50 years from now (given the uncertainty of the costs of climate change) - time preferences only exist for the costs/revenues of carbon projects, which have been discounted accordingly.
} 
ArborVitae Environmental Services. 1999. Estimating the carbon sequestration benefits of reforestation in Eastern Canada. Joint Forest Sector Table/Sinks Table, National Climate Change Process. Bahn, O., L. Barreto and S. Kypreos. 2001. Modelling and assessing inter-regional trade of $\mathrm{CO}_{2}$ emission reduction units. Environ. Model. Assess. 6: 173-182.

Bashkin, M. and D. Binkley. 1998. Changes in soil carbon following afforestation in Hawaii. Ecology 79: 828-833.

Bernard, A. and M. Vielle. 2003. Measuring the welfare cost of climate change policies: A comparative assessment based on the computable general equilibrium model GEMINI-E3. Environ. Model. Assess. 8: 199-217.

Bernoux, M., V. Eschenbrenner, C. Cerri, J. Melillo and C. Feller. 2002. LULUCF-based CDM: too much ado for a small carbon market. Clim. Policy 2: 379-385.

Betts, R. 2000. Offset of the potential carbon sink from boreal forestation by decreases in surface albedo. Nature 408(6809): 187-190.

Bhatti, J., M. Apps and C. Tarnocai. 2002. Estimates of soil organic carbon stocks in central Canada using three different approaches. Can. J. Forest Res. 32: 8055-812.

Bird, N. 2003. Preliminary forest carbon modelling of Labrador Forest Management District 19a. Woodrising Consulting Inc. for the Sierra Club of Canada. 42 p.

Bonnie, R., M. Carey and A. Petsonk. 2002. Protecting terrestrial ecosystems and the climate through a global carbon market. Tr. R. Soc. S-A. 360: 1853-1873.

Canada. 2005. Website: Defining greenhouse gas offsets system for Canada. www.climatechange.gc.ca/english/offsets/. Accessed April 14, 2005.

Chen, W., J. Chen, D. Price and J. Cihlar. 2002. Effects of stand age on net primary productivity of boreal black spruce forests in Ontario, Canada. Can. J. Forest Res. 32: 833-842.

Cherry, M. 2001. Options for allocation of afforestation stock in Ontario with anticipated climate change. Ontario Ministry of Natural Resources, Sault Ste Marie, ON. Forest Research Information Paper No. 148.36 p.

Christiansen, A. and J. Wettestad. 2003. The EU as a frontrunner on greenhouse-gas emissions trading: How did it happen and will the EU succeed? Clim. Policy 3: 3-18.

DeMarsh, P. 1999. Potential for afforestation on private woodlots in Canada. Canadian Federation of Woodlot Owners for Joint Forest Sector Table/Sinks Table, National Climate Change Process. 10 p.

Duinker, P. 1999. Estimating the carbon sequestration benefits of afforestation in Ontario, Quebec and the Atlantic provinces. ArborVitae Environmental Services, Woodrising Consulting Inc. for Joint Forest Sector Table/Sinks Table, National Climate Change Process. 97 p.

Forest Sector Table. 1999. Options Report: Options for the forest sector to contribute to Canada's national implementation strategy for the Kyoto Protocol. Forest Sector Table, Canadian Forest Service of Natural Resources Canada and Environment Canada, National Climate Change Process. 167 p.

Griss, P. 2002. Final report to the Pollution Probe forest carbon management workshop series. Pollution Probe: $79 \mathrm{p}$.

Gunter, W., S. Wong, D. Cheel and G. Sjostrom. 1998. Large $\mathrm{CO}_{2}$ sinks: their role in the mitigation of greenhouse gases from an international, national (Canadian) and provincial (Alberta) perspective. Appl. Energ. 61: 209-227.

Krcmar, E., B. Stennes, G. van Kooten and I. Vertinsky. 2001. Carbon sequestration and land management under uncertainty. Eur. J. Oper. Res. 135: 616-629.

Kurz, W. 1999. Assessing options for measurement of verifiable changes in carbon stocks from reforestation, afforestation, and deforestation and other potential forestry activities. ESSA Tech Ltd. for National Sinks and Issues Table, National Climate Change Process. 60 p.
Lecocq, F. and K. Capoor. 2005. State and trends of the carbon market 2005. Produced for Carbon Finance Project of the World Bank and the International Emissions Trading Association. 44 p.

Marbek Resource Consultants. 2004. Administration and transaction cost estimates for a greenhouse gas offset system - final report. Produced for Strategic Policy Branch, Agriculture and Agri-Food Canada. 73 p.

Marland, G. and B. Schlamadinger. 1997. Forests for carbon sequestration or fossil fuel substitution? A sensitivity analysis. Biomass Bioenerg. 13: 389-397.

McKenney, D., D. Yemshanov, D. Fox and E. Ramlal. 2004. Cost estimates for carbon sequestration from fast growing poplar plantations in Canada. For. Pol and Econ. 6: 345-358.

Miller, G. and D. Balsillie D. 2003. Public policy affecting afforestation and deforestation in Southern Ontario. XII World Forestry Congress Poster Session.

Peng, C., H. Jiang, M. Apps and Y. Zhang. 2002. Effects of harvesting regimes on carbon and nitrogen dynamics of boreal forests in central Canada: a process model simulation. Ecological Modelling 155: 177-189.

Perry, C., R. Miller and K. Brooks. 2001. Impacts of short-rotation hybrid poplar plantations on regional water yield. Forest Ecology and Management 143: 143-151.

Plonski, W.L. 1974. Normal yield tables (metric) for major forest species of Ontario. Ministry of Natural Resources.

Sager, J. 2003. An analysis with the CERT model of the FSU market power in the carbon emissions trading market. Environ. Model. Assess. 8: 219-238.

Samson, R., P. Girouard, C. Zan, B. Mehdi, R. Martin and J. Henning. 1999. The implications of growing short-rotation tree species for carbon sequestration in Canada. for Joint Forest Sector Table/Sinks Table, National Climate Change Process. 91 p.

Sandor, R., I. Swingland and E. Bettelheim. 2002. An overview of a free-market approach to climate change and conservation. Tr. R. Soc. S.-A. 360: 1607-1620.

Schlamadinger, B. and G. Marland. 1996. The role of forest and bioenergy strategies in the global carbon cycle. Biomass Bioenerg. 10: 275-300.

Schulze, E., R. Valentini and M.-J. Sanz. 2002. The long way from Kyoto to Marrakech: Implications of the KP negotiations for global ecology. Global Change Biol. 8: 505-518.

Seely, B., C. Welham and H. Kimmins. 2002. Carbon sequestration in a boreal forest ecosystem: results from the ecosystem simulation model, FORECAST. Forest Ecol. Manag. 169: 123-135.

Stiers, S. and S. Siebert. 2002. The Kyoto Protocol: an opportunity for biodiversity restoration forestry. Conserv. Biol. 16: 575-576.

Stocks, B., M. Fosberg, T. Lynham, L. Mearns, B. Wotton, Q. Yang, J.-Z. Jin, K. Lawrence, G. Hartley, J. Mason and D. McKenney. 1998. Climate change and forest fire potential in Russian and Canadian boreal forests. Climatic Change 38: 1-13.

van Kooten, G., E. Krcmar-Nozic, B. Stennes and R. van Gorkon. 1999. Economics of fossil fuel substitution and wood product sinks when trees are planted to sequester carbon on agricultural lands in Western Canada. Can. J. Forest Res. 29: 1669-1678.

Varma, A. 2003. UK's climate change levy: Cost effectiveness, competitiveness and environmental impacts. Energ. Policy 3: 51-61.

Vesterdal, L., E. Ritter and P. Gundersen. 2002. Change in soil organic carbon following afforestation of former arable land. Forest Ecol. Manag. 169: 137-147.

West, T. and W. Post. 2002. Soil organic carbon sequestration rates by tillage and crop rotation: a global data analysis. Soil Sci. Soc. Am. J. 66(6): 1930-1946.

White, T. and W. Kurz. 2003. Carbon credits and afforestation. Can. Silvic. Winter: 13-15.

Williams, J. and P. Griss. 1999. Design and implementation options for a national afforestation program(s). Arborvitae Environmental Services for National Sinks and Forest Sector Issues Tables, National Climate Change Process. 55 p. 